\title{
DIAGNÓSTICO E ANÁLISE DA BALNEABILIDADE DA ÁREA DE PROTEÇÃO AMBIENTAL DA LAGOA DE CIMA, LOCALIZADA NO MUNICÍPIO DE CAMPOS DOS GOYTACAZES/RJ
}

\author{
Rafael Carvalho dos Santos', Bárbara Mercadante de Resende ${ }^{1}$, Ana Caroline Alves Rodrigues', \\ Kamila Sales Velasco', Frank de Souza Pavan ${ }^{2 *}$
}

\section{RESUMO}

SANTOS, R.C.; RESENDE, B.M.; RODRIGUES, A.C.A.; VELASCO, K.S.; PAVAN, F.S. Diagnóstico e Análise da balneabilidade da área de proteção ambiental da Lagoa de Cima, localizada no Município de Campos dos Goytacazes/RJ. Perspectivas Online: Exatas \& Engenharias, v. 7, n.18, p.41-51, 2017.

A água é um dos mais importantes recursos naturais, cuja falta ou alterações significativas nos padrões da qualidade, pode tornar-se fator limitante para o desenvolvimento agrícola, urbano, industrial e para usos específicos dos seres humanos. Sua disponibilidade, em quantidade e qualidade, é uma contínua preocupação em função, principalmente, do crescimento populacional, das incertezas a respeito dos fatores climáticos e da crescente poluição dos mananciais ainda disponíveis. No município de Campos dos Goytacazes, região norte do estado do Rio de Janeiro, existe um conjunto de lagoas que são utilizadas para fins consuntivos e não consuntivos, de uso direto e indireto. Entre elas destaca-se a Lagoa de Cima, que fica localizada em uma área de proteção ambiental (APA), muito utilizada por moradores locais e turistas. Com a intenção de promover a segurança para os usuários desse ecossistema, a pesquisa teve como objetivo realizar um diagnóstico da qualidade da água e analisar a balneabilidade da lagoa. Para a realização da pesquisas foram realizadas incursões no entorno do corpo hídrico e com a utilização de um Global Positioning System (GPS) foi possível identificar os usos específicos. Tendo em vista que a pesquisa foi iniciada no mês de dezembro de 2016, até o momento (maio de 2017), apresentamse como resultados parciais, os pontos com identificação e classificação dos usos. Os demais objetivos específicos serão: coletar amostras da água nos pontos identificados; elaboração de um mapa com a identificação dos parâmetros da qualidade da água. Conclui-se, até o momento, que os usos na Lagoa de Cima são significativos e em sua maioria de contato direto. Esse fato ratifica a necessidade de identificação dos parâmetros de qualidade do corpo hídrico.

Palavras chave: Balneabilidade. Lagoa de Cima. Qualidade da água. 


\begin{abstract}
Water is one of the most important natural resources, and the significant changes in water quality can become a limiting factor for agriculture, urban, industrial development and for humans supply. Their availability, in quantity and quality, is a continuous concern mainly due to the population growth, as well as the uncertainties regarding climatic factors and the due the increase of pollution and limiting the availability of water sources. In the municipality of Campos dos Goytacazes, in the northern region of the Rio de Janeiro State, there is a several lagoons that are used for different purposes and, direct and indirect use. Among them the Lagoa de Cima, which is located in an area of environmental protection
\end{abstract}

ABSTRACT
(AEP), is much used by local residents and tourists for recreation. With the intention of promoting safety for the users of this ecosystem, the research aims to make a diagnosis of the water quality and its bathing. For the accomplishment of the researches were made visits in the surroundings of the water body to identify the specific uses. Considering that this research started in December 2016, we have partial results. The other specific objectives will be: to collect water samples and prepare a map with the identification of water quality parameters. Concluding, the date showed a significant use for recreation with direct contact and needs to identify the critical parameters of water quality.

Key-words: bathing. Lagoa de Cima. Water quality.

\footnotetext{
${ }^{1}$ Institutos Superiores de Ensino do CENSA - ISECENSA - Acadêmico do Curso de Graduação em Engenharia de Produção - Rua Salvador Correa, 139, Centro, Campos dos Goytacazes, RJ, CEP: 28035-310, Brasil;

${ }^{2}$ Institutos Superiores de Ensino do CENSA - ISECENSA - Laboratório de Engenharia - Rua Salvador Correa, 139,

Centro, Campos dos Goytacazes, RJ, CEP: 28035-310, Brasil;
} 


\section{INTRODUÇÃO}

A água representa um insumo fundamental para o sustento do planeta. De fato, os seres vivos não possuem autossuficiência em seus organismos que os condicionem a viver sem a água. Do ponto de vista social, a interferência da água traz alterações significantes nos ambientes, tendo em vista que pode ser um instrumento de movimentação ou de transformação na economia (PAVAN, 2015).

Os corpos d'água estão em contínua interação com os outros compartimentos ambientais. A qualidade da água de um sistema aquático (rio ou lago) varia em função de fenômenos naturais (períodos de estiagem e de chuva, flutuação de nível de rios e lagos, tipologia de solo marginal) e de atividades antrópicas desenvolvidas na área de drenagem da bacia hidrográfica. Assim, tudo o que ocorre na área de drenagem de uma bacia hidrográfica refletirá em flutuações da qualidade das águas do corpo hídrico receptor. A água dilui e solubiliza praticamente todas as substâncias, atuando como um veículo de ligação entre os ambientes terrestres e aquáticos. Por outro lado, os corpos hídricos, principalmente os de maior grandeza, possuem a capacidade de autodepuração, permitindo, assim, o restabelecimento do equilíbrio aquático por mecanismos essencialmente naturais (VON SPERLING, 2007).

Do ponto de vista social, o recurso hídrico bem gerenciado pode transformar ambientes que podem se tornar áreas próprias e, ao mesmo tempo, impróprias para viver, tendo em vista a forma como é gerenciada. São justamente estes fatores que fazem com que a água se torne um recurso passível de conflito, ou seja, desde o momento em que passou a se tornar um recurso, a sociedade discute as suas relações (PAVAN, 2015).

Como bens naturais urbanos vulneráveis, lagos e lagoas são características da paisagem que contribuem, significativamente, para aumentar a qualidade de vida nos centros urbanos, proporcionando espaço para atividades recreativas e educativas e, até mesmo contribuindo para amenizar o clima urbano (MARTÍNEZ-ARROYO e JÁUREGUI, 2000).

A APA da Lagoa de Cima, é muito utilizada por banhistas, para atividades náuticas, para a pesca, para a captação de água pela população que vive no entorno e, para atividades esportivas de contato direito e indireto. Neste sentido, esta pesquisa teve como objetivo realizar um diagnóstico da qualidade da água e analisar a balneabilidade da Lagoa de Cima, localizada no município de Campos dos Goytacazes RJ. Para alcançar o objetivo proposto foram estabelecidos os seguintes objetivos específicos: identificar os locais com maior frequência de banhistas ou usuários que tenham contato direto e ou indireto com a água; demarcar geograficamente os pontos identificados no objetivo anterior; fazer coleta da água nos pontos georreferenciados e realizar análises dos parâmetros químicos, físicos e biológicos das amostras coletadas; elaborar um mapa de localização com a identificação dos possíveis locais apropriados quanto à balneabilidade, identificando os parâmetros da qualidade da água encontrados.

Tendo em vista que pesquisa foi iniciada no mês de dezembro de 2016, até o momento, apresentamse como resultados parciais, os pontos com identificação dos usos, sua a tipologia e classificação. As próximas ações da pesquisa serão a coleta de água para análises e definição dos parâmetros. 


\section{PERSPECTIVASonline}

\section{METODOLOGIA}

\section{1. Área do Estudo}

A Lagoa de Cima está inserida na bacia de drenagem do Rio Imbé e Lagoa de Cima que abrange grande parte da região serrana do norte fluminense, englobando os municípios de Santa Maria Madalena, Trajano de Morais e Campos dos Goytacazes e para este último totaliza uma área de $860 \mathrm{~km}^{2}$. A Área de Proteção Ambiental da Lagoa de Cima localiza-se no distrito de Ibitióca, parte oeste do município de Campos dos Goytacazes, situado na região norte do estado do Rio de Janeiro (REZENDE et al, 2006).

Situada a 28 quilômetros do centro urbano do município de Campos, é abastecida pela convergência dos Rios Urubu, Imbé e alguns córregos que, em conjunto, resultam em uma área de drenagem de $986 \mathrm{~km}^{2}$, criando um espelho d'água com 14,95 km² de área e $18 \mathrm{~km}$ de circunferência (BIDEGAIN et al 2002).

A lagoa ainda recebe a drenagem hídrica oriunda da Serra do Desengano, região serrana do norte fluminense, que detém notável cobertura de remanescentes da Mata Atlântica, englobada nos limites do Parque Estadual do Desengano. Dentre as importâncias da Lagoa de Cima está o fato de que é do seu interior que surge o Rio Ururaí, que após percorrer $48 \mathrm{~km}$ se torna um dos principais tributários da Lagoa Feia, maior lagoa de água doce do país (BIDEGAIN et al., 2002; REZENDE et al., 2006)

Vale ressaltar, que a Lagoa de Cima é muito utilizada para atividades de lazer com usos de contato direto e indireto da água, durante o ano. Especificamente no período do verão ocorre o aumento da frequência dos banhistas de toda a região.

\subsection{Procedimentos Técnicos}

\subsubsection{Identificação dos locais de maior concentração de usuários}

Para identificar os locais com maior frequência dos usuários, bem como os usos específicos de contato direto e indireto com a água, foram realizadas incursões a campo, em períodos distintos, sendo uma no mês de dezembro de 2016, duas no mês de janeiro, e uma no mês de fevereiro de 2017. Em virtude da confirmação de casos de febre amarela na região, foi necessário suspender as pesquisas de campo, a partir do mês de março de 2017.

Na primeira visita a campo foi possível reconhecer parte do ambiente a ser pesquisado Nesta mesma etapa iniciou o processo de identificação dos usos. Com a utilização de uma câmera fotográfica da Marca NIKON Mod. Coolpix P500, 36x optical zoom, wide full hd foram realizados registros de imagens dos locais identificados.

\subsubsection{Georeferenciamento dos pontos}

Com a utilização de um GPS da marca Garmin etrex (Figura 1) foram identificadas as coordenadas geográficas dos locais onde há usuários, e, inclusive banhistas. 


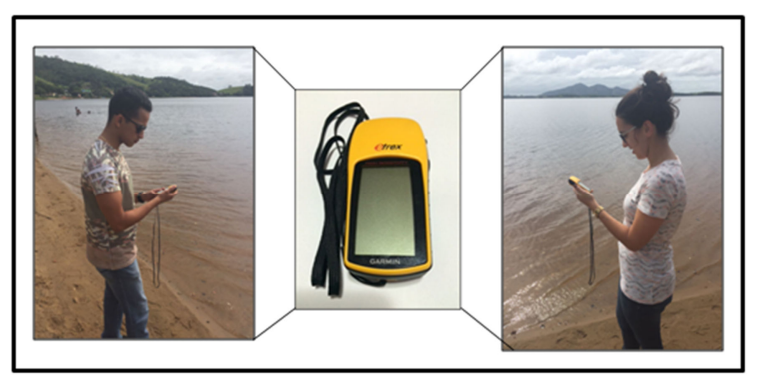

Figura 1: Alunos do Projeto utilizando o GPS para definir as coordenadas geográficas.

Os registros das coordenadas geográficas foram realizados nas incursões a campo. À medida que eram identificados, visualmente, os usuários, um ponto era registrado no GPS.

\subsubsection{Mapa Temático}

Para a confecção dos mapas foi utilizada a base cartográfica do Google Earth, versão 2016. As coordenadas registradas no GPS foram inseridas na imagem de satélite e identificados os locais visitados.

Após o registro dos pontos, foi editada uma legenda para os locais, e com a utilização do software mapWindow editou-se um mapa temático. Para representar a classificação dos usos (consuntivos/não consuntivos e diretos/indiretos) foi elaborado um quadro, por meio do Microsoft office Word versão 2013.

Para Robinson (1984) os mapas temáticos são diferentes dos mapas em geral. Enquanto mapas convencionais buscam representar a posição relacionada a uma variedade de diferentes características em um mapa, os mapas temáticos se concentram em representar as variações espaciais de uma única feição ou sua relação com outras. Nos temáticos o objetivo é a representação entre a forma e a estrutura da distribuição, que é a característica do todo e a inter-relação das feições. Para o autor, não existem restrições quanto se trata de mapas temáticos.

\section{RESULTADOS PARCIAIS E DISCUSSÕES}

\subsection{Identificação dos locais e reconhecimento da área}

Na primeira visita a campo, realizada no mês de dezembro de 2016, foi possível identificar usos distintos e entre eles destacam-se a pesca e o banho (Figura 2).

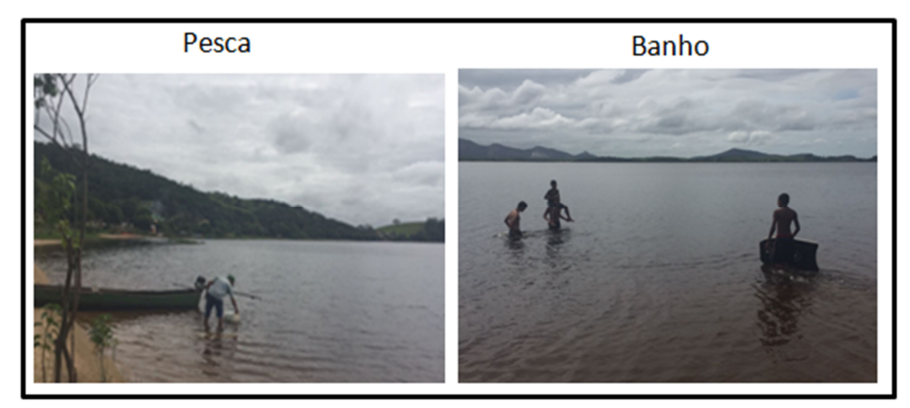

Figura 2: Pescador preparando o barco para o uso e moradores (crianças) tomando banho. 
De acordo com os moradores, é bem comum o uso da lagoa para o banho, principalmente quando a qualidade da água de abastecimento parece não estar atendendo aos parâmetros de qualidade estabelecidos pela Portaria do Ministério da Saúde $\mathrm{n}^{0}$ 2.914/2011. Relataram ainda que muitas vezes a água da concessionária "chega com cheiro ruim" e isso os motiva a tomar banho na lagoa.

Nas demais incursões a campo foi identificada uma associação de pescadores na comunidade de São Bento, localizada no entorno da lagoa (Figura 3).

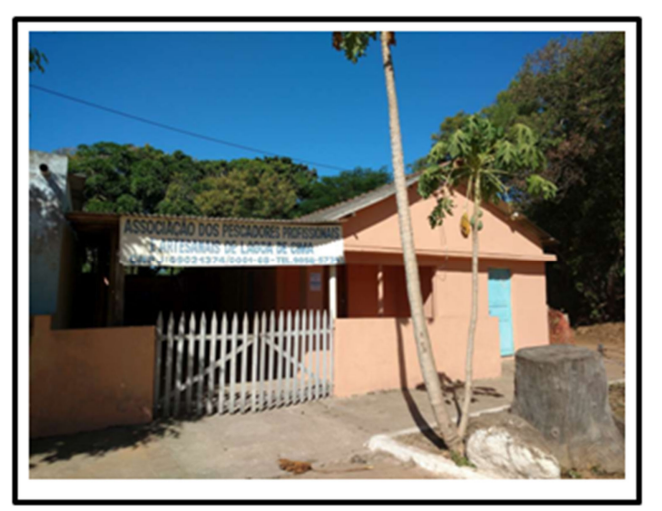

Figura 3: Associação de Pescadores de São Bento

Ao serem entrevistados, informalmente, alguns pescadores informaram que "acreditam que a água da lagoa é muito boa, tendo em vista que há presença de peixes grandes”. Informaram ainda, que é possível pescar em todos os pontos da área, inclusive nas áreas próximas as residências, que muitas vezes concentram-se os cardumes.

A presença dos cardumes pode ser proveniente do lançamento de restos de alimentos das próprias casas. Vale ressaltar, que no mesmo local onde esses alimentos são lançados e provocam a concentração dos peixes, muitas vezes, são os locais de lançamento do esgoto domiciliar, pois as fossas de algumas casas já não comportam a quantidade de efluente gerado.

Também foi possível identificar no entorno da lagoa, mais precisamente à margem direita, a presença de bares e ocupações, com cadeiras e mesas (Figura 4).

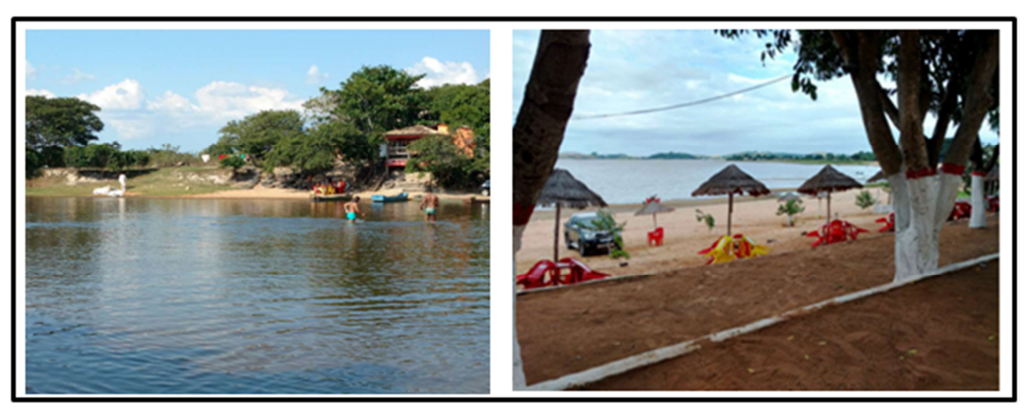

Figura 4: Vista panorâmica de bares localizados o entorno da Lagoa de Cima. 
De acordo com os proprietários dos bares, os dias de maior frequência na localidade são os sábados, domingos e feriados. Os usuários levam suas famílias para os restaurantes e bares, tomam banho na lagoa e aproveitam para beber, comer e confraternizar com amigos.

Na margem esquerda, pode-se verificar o Iate Clube da Lagoa de Cima, uma área muito utilizada para banho, principalmente no verão (Figura 5).

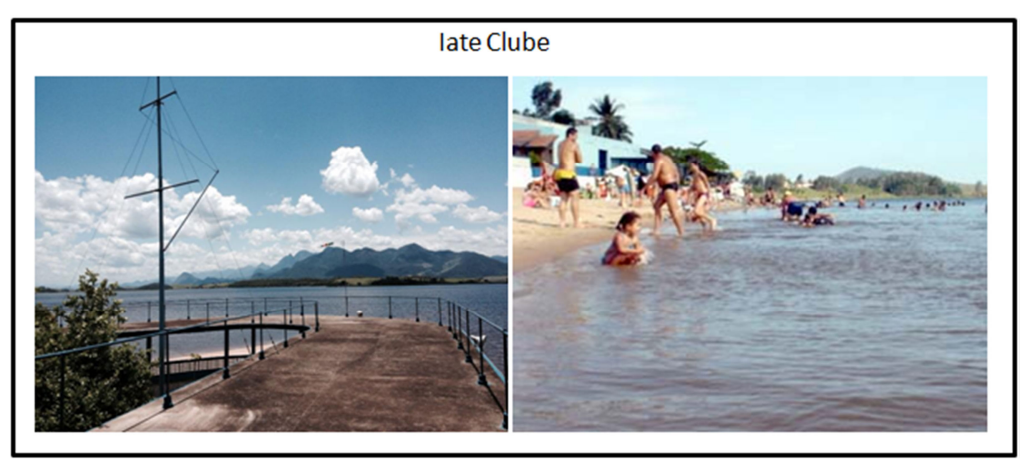

Figura 5: Vista panorâmica do Iate Clube da Lagoa de Cima

Ao ser entrevistado, um usuário do Iate Clube informou que a Lagoa de Cima é o lugar mais adequado da região de Campos dos Goytacazes RJ, para a prática de atividades náuticas, tendo em vista que o volume de água da lagoa é apropriado para a utilização lanchas, jetski e até mesmo para a natação.

Uma segunda entrevistada, atleta da modalidade Stand Up Paddle - SUP há três anos, informou que a Lagoa de Cima, além de possuir volume de água, torna-se mais apropriada para a prática desse esporte, pois apresenta condições climáticas ótimas, como o vento, por exemplo, que pode influenciar negativamente nessa atividade esportiva (Figura 6).

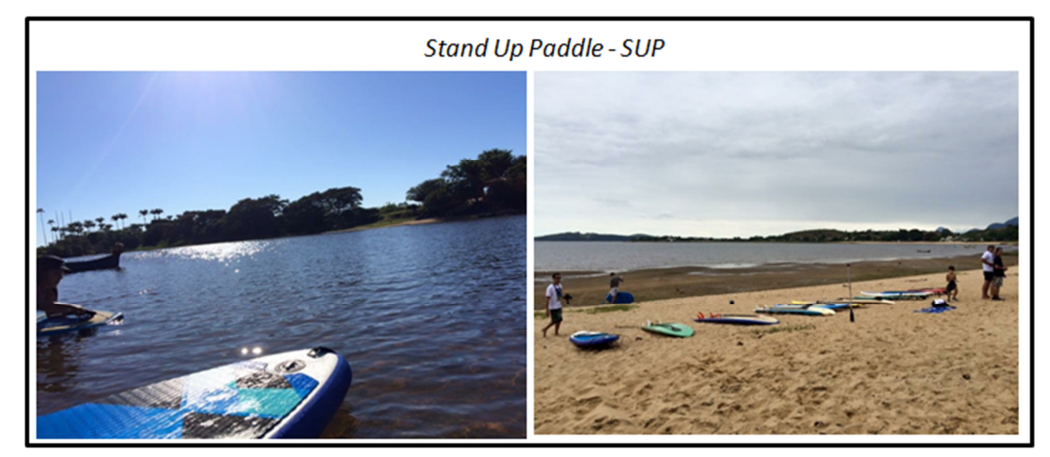

Figura 6: Vista panorâmica da prática de SUP

Outro registro que vale considerar é a dessedentação de animais (Figura 7). Foi possível verificar, em todas as saídas de campo, a presença de animais na lagoa, inclusive em áreas que foram cercadas artificialmente pelo possível proprietário dos animais, para mantê-los próximo d'água. 


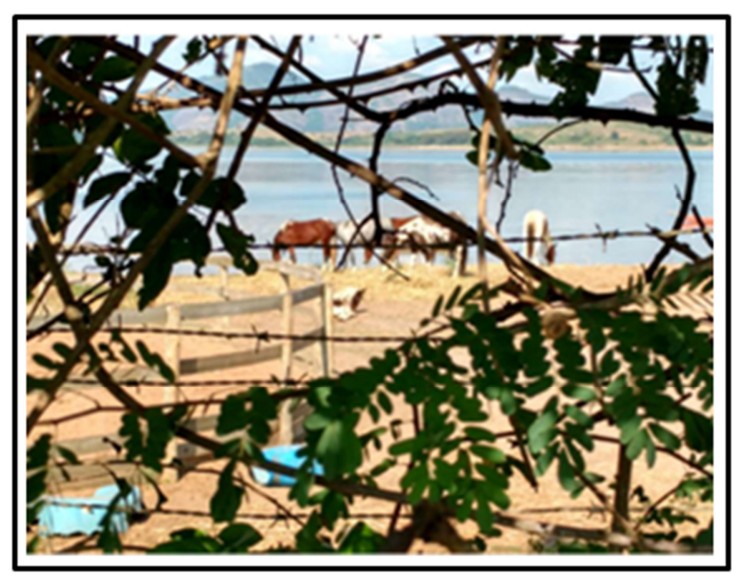

Figura 7: Dessedentação de animais próximo ao espelho d'água

\subsection{Classificação dos usos e georeferenciamento}

De acordo com a ANA (2005) o uso consuntivo refere-se aos usos que retiram a água de sua fonte natural diminuindo suas disponibilidades quantitativas, espacial e temporalmente enquanto o uso não consuntivo refere-se aos usos que retornam à fonte de suprimento, praticamente a totalidade da água utilizada, podendo haver alguma modificação no seu padrão temporal de disponibilidade quantitativa.

Verificou-se na pesquisa de campo que a maior parte dos usos são de contato direto com, exceção da pesca que é de contato indireto, e dos esportes que se diferencia a natação (contato direto) do prática de iatismo, vela, remo e Stand Up Paddle - SUP (contato indireto). Foram classificados como usos não consuntivos, pois não alteram a quantidade/qualidade da água (Quadro 1).

Oportunamente, nas visitas a campo, foi possível identificar e classificar os usos (Quadro 1).

Quadro 1. Quantidade usos e tipo de usos

\begin{tabular}{|l|l|l|}
\hline USO & TIPO & CLASSIFICAÇÃO \\
\hline Banho & Direto & Não Consuntivo \\
\hline Pesca & Indireto & Não Consuntivo \\
\hline Esporte & Direto/Indireto & Não Consuntivo \\
\hline $\begin{array}{l}\text { Dessedentação de } \\
\text { animais }\end{array}$ & Direto & Não Consuntivo \\
\hline & & \\
\hline
\end{tabular}

Importante ressaltar, que a dessedentação de animais é considerada um uso consuntivo, quando há retirada de volume de água de um manancial, para abastecer reservatórios, que serão utilizados para saciar a sede dos animais. A dessedentação verificada na pesquisa está relacionada com a presença do animal, no 
entorno da lagoa, fato que não altera significativamente o volume de água disponível e por isso foi considerado como uso não consuntivo.

Para melhor representar os locais referentes aos usos, foram registradas coordenadas geográficas, nos locais específicos (Figura 8).

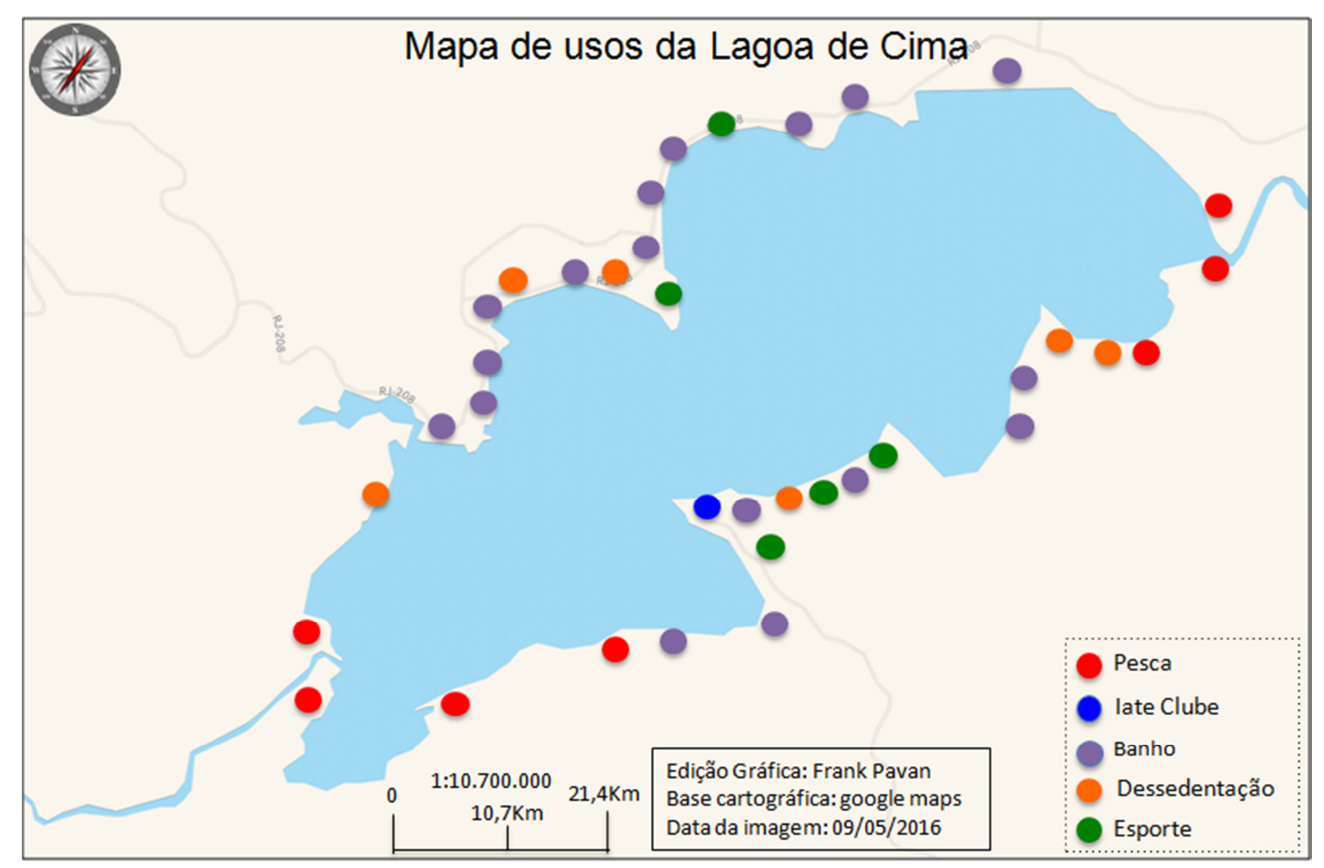

Figura 8: Mapa temático georreferenciado com usos registrados

É possível observar, na Figura 8, que existem usos em todo entorno da lagoa, e que esses usos, em algumas regiões, ocorrem simultaneamente no mesmo local, como é o caso do banho e dos esportes, e da pesca e dessedentação dos animais.

Vale ressaltar, que é recorrente, nas áreas identificadas (Figura 8) com maior fluxo de banhistas, as pessoas cozinhando e fazendo churrasco (Figura 9), principalmente nos finais de semana e no período do verão, quando é o número de visitantes na Lagoa de Cima se intensifica.

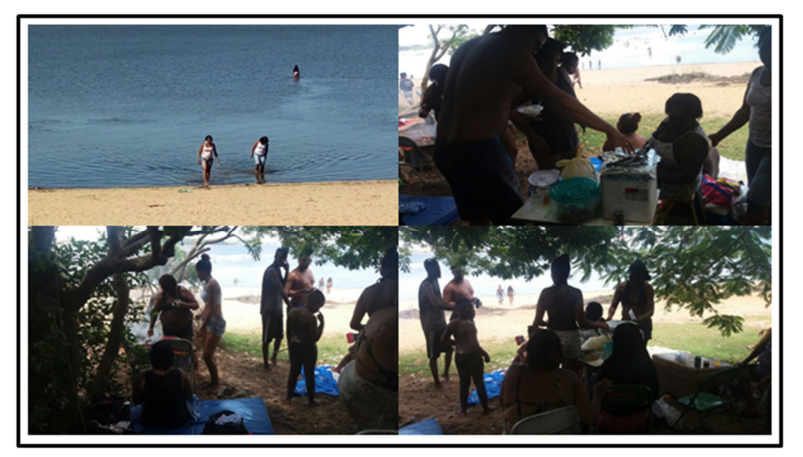

Figura 9: Vista panorâmica dos usuários utilizando a Lagoa e o entorno 


\section{CONCLUSÕES}

A região norte fluminense, no passado, foi considerada uma região pantaneira em face da quantidade de lagoas existentes. Atualmente, existem formalmente 14 lagoas registradas pelos órgãos competentes e entre elas está a Lagoa de Cima, classificada como unidade de conservação de uso sustentável, na categoria de Área de Proteção Ambiental (APA).

Pelos resultados preliminares da pesquisa, representados pelo mapa e pelas imagens, pode-se concluir que a Lagoa de Cima é um ecossistema de relevante valor ecológico e também econômico, principalmente para os moradores daquela região, que vivem da pesca e da exploração do turismo, mais precisamente no período do verão, época em que as pessoas se deslocam dos centros urbanos para a APA, com a intenção de praticar esportes, tomar banho e confraternizar com amigos e familiares.

Conclui-se ainda, que o geoprocessamento é uma ferramenta capaz de trazer uma melhor visualização das atividades destacadas na pesquisa. Pelo mapa apresentado nos resultados, pode-se verificar que os usuários se distribuem em toda extensão da lagoa e, que os usos não consuntivos e de contato direto são os de maior representatividade, fato que comprova a necessidade de analisar os parâmetros de qualidade da água da lagoa.

\section{LIMITAÇÕES DA PESQUISA}

No mês de fevereiro de 2017 foi anunciado, por meio dos órgãos oficiais do governo, um alerta sobre possíveis casos de febre amarela na região. As atividades da pesquisa exigem coleta de dados em campo. Para não colocar os alunos e os professores em risco, nas atividades de campo para coleta de dados, sugeriu-se a suspensão da pesquisa até que seja normalizado, formalmente, o problema, para garantir da segurança dos pesquisadores na área explorada.

\section{REFERÊNCIAS BIBLIOGRÁFICAS}

ABNT. NBR9897. 1987a. Planejamento de amostragem de efluentes líquidos e corpos receptores. Associação Brasileira de Normas Técnicas.

ABNT. NBR9898. 1987b. Preservação e técnicas de amostragem de efluentes líquidos e corpos receptores. Associação Brasileira de Normas Técnicas. ANA. 2011. Guia nacional de coleta e preservação de amostras: água, sedimento, comunidades aquáticas e efluentes líquidos.

ANA. Agência Nacional de Águas. Curso de Aperfeiçoamento em Recursos Hídricos. 2005. Disponível em:< http://capacitacao.ana.gov.br/Lists/Editais_Anexos/Attachments/23/05.RecursosHD-220909.pdf $>$. Acesso em: mar. 2017. 
BIDEGAIN, P.; BIZERRIL, C.; SOFFIATI, A. Lagoas do Norte Fluminense, Perfil Ambiental. SEMADS, Rio de Janeiro, 148p. 2002.

Companhia Ambiental do Estado de São Paulo. Organizadores: Carlos Jesus Brandão. [et al.]. -- São Paulo: CETESB; Brasília. 326 pp. APHA, AWWA, WEF. 2012.

MARTÍNEZ-ARROYO A. e JÁUREGUI E. On the environmental role of urban lakes in Mexico City. UrbanEcosystems 4. 2000.

MIGUEL, P. A. C. Estudo de caso na engenharia de produção: estruturação e recomendações para sua condução. Revista Produção, v. 17, n.1, p. 216-229, Jan. / Abr. 2007.

GIL, A. C. Como Elaborar Projetos de Pesquisa. 4. ed. São Paulo: Atlas, 2008. 175p.

PAVAN, F.S. Proposta para aperfeiçoamento da gestão de recursos hídricos em lagoas urbanas. Tese (Doutorado) - UFRJ/ COPPE/ Programa de Engenharia Civil. Rio de Janeiro: UFRJ/COPPE, 2015.

REZENDE, C. E. et al. Diagnóstico ambiental da área de proteção ambiental Lagoa de Cima. Rio de Janeiro: Universidade Estadual do Norte Fluminense Darcy Ribeiro: Centro de Biociências e Biotecnologia: Laboratório de Ciências Ambientais, 2006.

ROBINSON, Arthur H. Elements of cartography. 5th. Ed. New York: John Wiley \& Sons - usar J.Wiley, 1984.

SILVA, E. L.; MENEZES, E. M. Metodologia da Pesquisa e Elaboração de Dissertação. 3.ed. Florianópolis: Laboratório de Ensino a Distância da UFSC, 2001. 121p.

Standard Methods for examination of water and wastewater. 22nd ed. Washington: American Public Health Association. 1360 pp. AYRES, M. J.; AYRES, D. L. \& SANTOS, A. S. 2000.

VON SPERLING, M. 2007. Estudos e modelagem da qualidade da água de rios. Marcos von Sperling. Belo Horizonte: Departamento de Engenharia Sanitária e Ambiental - Universidade Federal de Minas Gerais. (Princípios do tratamento biológico de águas residuárias, v.7). 588pp. 